\title{
Intelligent Farming using Internet of Things and Cloud Computing
}

\author{
J. Nandhini, PhD \\ Prof \& Head/ ECE \\ Jai Shriram Engineering College \\ Tirupur, Tamilnadu, India
}

\author{
A.S. Narmadha \\ Assistant Professor / ECE \\ Jai Shriram Engineering College \\ Tirupur, Tamilnadu, India
}

\author{
G. Kalaiarasi \\ Assistant Professor / ECE \\ Jai Shriram Engineering College \\ Tirupur, Tamilnadu, India
}

\begin{abstract}
With the arrival of latest technologies, Internet of Things (IoT) becomes popular not only in industries but also in agriculture. Agriculture is the key to the event of human civilization and when population increases, it's necessary to extend the productivity with decrease in cost, time and human effort also increases. Hence the concept of IoT is employed to satisfy those needs. The prevailing method of agriculture consumes plenty of manual work. The farmers felt difficult to monitor the field condition from anywhere and at any time. Therefore the parameters associated with the agriculture like temperature, humidity, rain, moisture etc., are collected with the assistance of sensors and notified immediately to the farmers using IoT technology. The agriculture system proposed is integrated with IoT, Raspberry $\mathrm{Pi}$ and sensors to enhance the agricultural efficiency. Live information feed is obtained online from thingspeak.com. In this system, all the activities in farming are monitored and controlled by farmers from pre-farming to post-farming with the assistance of this mobile devices and be advised $24 * 7$. Animal detection is added advantage to the present system by detecting the presence of animal and offers a warning. Animal interference in residential areas is increasing day by day which affects the life of human and natural properties. This system is feasible to prevent both animal and human life.
\end{abstract}

\section{General Terms}

Automated farming, IoT, Agriculture, Temperature, Humidity, Rain, Moisture

\section{Keywords}

Raspberry Pi, PIR sensor, Agriculture, Smart Farming.

\section{INTRODUCTION}

Indian Economy's strength and backbone depends on Agriculture. Most of the India's population depends on agriculture but they're facing lot of problems due to deforestation, atmospheric condition, Industrialization etc... Improving farm yield is crucial to satisfy the rapidly growing demand of food for growth in India. This happens mainly because of lack in knowledge/advice and difficulties in monitoring and difficulty in doing essential activities required for agriculture. By seeing this scenario of agriculture which is surrounded by loads of issues, its utmost requirement is to own IoT based smart farming. IoT encompasses many new intelligent concepts for the near future like smart home, smart city, smart transportation and smart farming.

Smart farming is a capital-intensive and hi-tech system of growing food cleanly and sustainable for the masses. It is the application of modern Information and Communication
Technologies (ICT) into agriculture. The Intelligent farming along with Embedded IoT could be called a connected farm to support a large number of devices from varying agricultural product manufacturers. The important - time environmental parameter like soil moisture level, temperature, water level and rain are collected from the farm using different sensors and intimated immediately to the farmer.

The massive amount of information generated by the wireless sensor network is stored and processed using cloud computing. Automation in agriculture is done in the proposed system and also it assists the farmers to do the necessary action required without manual intervention. It uses Raspberry Pi to update the environmental status to the farmer through IoT technology. Internet of Things Cloud Service creates excessive communication between inexpensive sensors in the IoT which means even greater connectivity [11].

Chapter 1 presents about the Introduction to the work. Chapter 2 provides the literature and discusses the various works taken by the researches. Chapter 3 presents the existing system. Chapter 4 discusses the system description and working principle of the proposed system. Chapter 5 discusses the results obtained using various parameters. Chapter 6 summarizes and concludes the work.

\section{LITERATURE SURVEY}

Asres Temam Abagissa et.al [1] proposed Smart Agricultural Device Controlling System based on IoT that's intended to form farming automated and enhance crop productivity. Information collected from sensors are transmitted through the cellular network and interpreted by the system to require corrective and preventive measures. Shweta B Saraf et.al [2] proposes wireless communication system based on cloud to monitor and control a set of sensors and actuators to assess the plants water need. Implementation of soil moisture based automated irrigation system reduced the consumption of water.

Abhishek Kumar et.al [3] used moisture sensor to live the moisture level of the various plants and send the signal to the Arduino board which triggers the pump to show on and provide the water to respective plant using the rotating platform/sprinkler.

Rahul Dagar et.al [4] proposed a straight forward architecture of IoT sensors to collect the information and send it over the Wi-Fi network to the server, so that it can take actions counting on the knowledge. Prajna $P$ et.al [5] proposed IoT based Wild Animal Intrusion Detection System, to monitor the sector using sensor and camera to capture the image of the intruder. Classified images are processed using image processing for taking suitable actions. 
Rajalakshmi R et.al [6] developed IoT based agriculture stick for live monitoring of temperature, humidity, soil moisture, electrical conductivity and rain condition using Arduino and Cloud computing. Shruthi Bansod et.al [7] proposed Arduino based Water Irrigation System to take the inputs from both the sensors. Based on the inputs from the spoil sensor, the system will decide the quantity of water to be supplied to the farm. It reduces manual work of the farmers and help to utilize the resources by eliminating manual switching mechanism.

Vikhram B et.al [8] developed Animal Detection System in Farm Areas, where it uses PIR and ultrasonic sensor to detect the movement of the animal and send signal to the controller. It diverts the animal by producing sound and signal is transmitted to GSM. The system supplies the response to farmers and forest department immediately.

\section{EXISTING SYSTEM}

Smart farming using IoT is developed with different measures that are needed for the agriculture. In fact a huge number of research works are done to enhance the functioning of the agricultural field. By using the statistical data collected from the sensors (like temperature, humidity, moisture and light intensity sensor), watering and roofing of green houses are controlled using Arduino [9,10]. The collected data are compared with the weather forecast for decision making. The system is implemented with sensor to monitor the information and transmit it through a web server to the farmer using IoT technology.

The system described above is similar in the context of wireless sensor node. The only difference is the usage of communication technologies and the data storage from the nodes. When the quantity of node is increased, the server need more space for storage thus resulting in increasing of cost. This paper proposes Intelligent farming system with sensor network, cloud computing with IoT communication technology to enhance the performance of the system and data storage.

\section{PROPOSED SYSTEM}

The proposed system helps to improve the quality and quantity of the farm by monitoring the field and taking necessary actions without any human intervention. The combination of IoT and cloud computing can be more efficient. This system collect the environmental parameters from various sensors installed in an agriculture field such as moisture, temperature, rainfall etc., The sensed data is stored in cloud through IoT gateway (Thingspeak) which provides real time visualization of data.

The cloud server performs decision making by comparing the sensed values and predefined threshold values are fed into the cloud as per the crop selection. For better performance, Raspberry Pi is used here instead of Arduino. In addition, PIR sensor and ultrasonic sensor is used to detect the presence of animal into the farm and send an input signal to the controller. Immediately the board is turned on and a sound from the system will divert the animal out of the farm. This system will not be dangerous to animal and human being and it protects the farm. Considering the climatic conditions, the system will provide suggestions to the farmers regarding planting the crops.

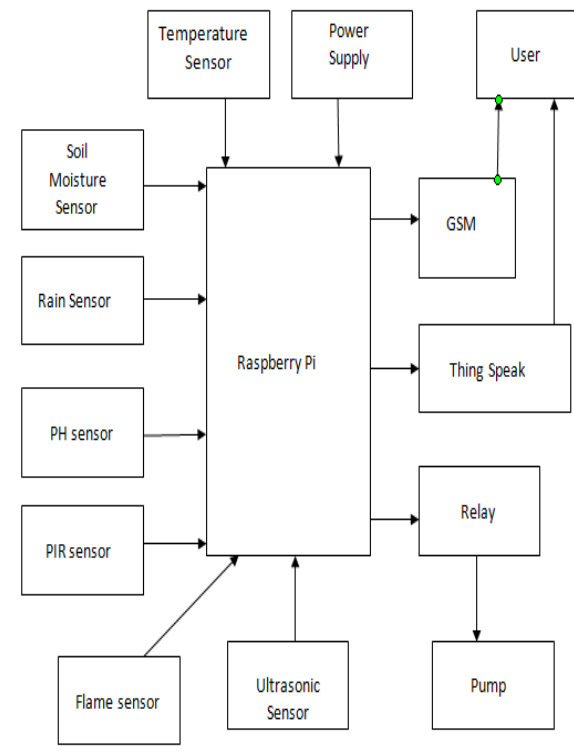

Fig 1: Block diagram of Proposed System

\subsection{Raspberry Pi}

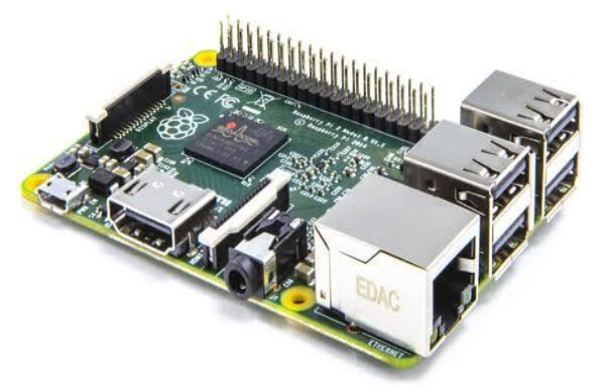

Fig 2: Raspberry Pi

In IoT, Raspberry Pi is an important device for computing and networking operations. It offers remote location controlling with the help of automation. Various versions of Raspberry Pi are available. The components used in the system are Rasperry Pi Version 3, ARM Cortex and 1 GB RAM. It also comprises of 40 GPIO pins, $3.5 \mathrm{~mm}$ audio jack, Full HDMI ports, Ethernet port, 4 USB ports, Micro SD card slot, the Display interface(DSI) and video camera interface (CSI).

\subsection{DHT 11 Sensor}

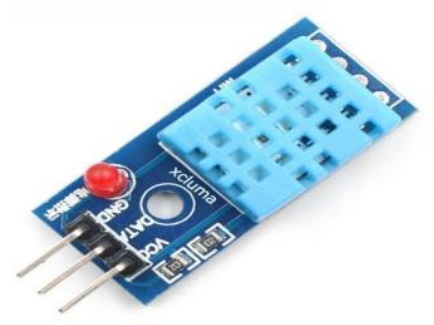

Fig 3: DHT 11 Sensor

DHT11 Temperature \& Humidity Sensor complex with a calibrated digital signal output. High reliability and long term stability can be achieved by using digital-signal- acquisition technique and temperature \& humidity sensing technology. It has a resistive-type humidity measurement component and NTC temperature measurement component. It offers excellent 
quality, fast response, anti- interference ability and costeffectiveness by connecting with 8 bit microcontroller.

\section{3 pH sensor}

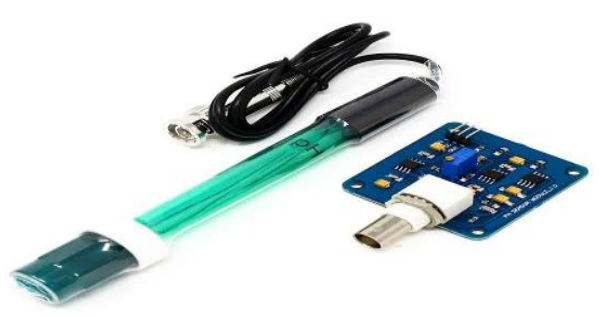

Fig 4: pH Sensor

$\mathrm{pH}$ is measured in different applications: medical, environmental, food production, safety appliances and in industry for process control. $\mathrm{pH}$ is measured using Litmus paper, $\mathrm{pH}$ sensitive glass electrode, sensors with ion selective layers on FETs, etc. $\mathrm{pH}$ sensor measures the acidity and alkalinity of the soil. The optimal $\mathrm{pH}$ range of plants is between 5.5 and 7.0. If it beyond the level then, it shows the notification to the farmer immediately.

\subsection{Soil Moisture Sensor}

Moisture of the soil can be tested using this sensor. When the soil is having water shortage then the output will be high otherwise it will be low. Automatic watering of plant is done by using this sensor. The sensor works on the principle of open short and produces both analog and digital output.

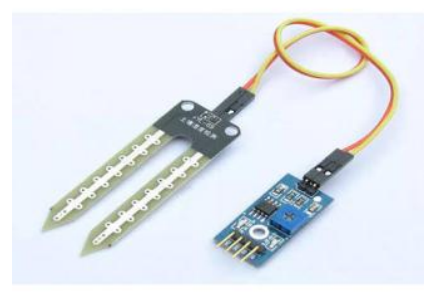

\section{Fig 5: Soil Moisture Sensor}

When the soil is dry, there's no passage of current and act as an electrical circuit. But, when the soil is wet passage of current exists and also the circuit is claimed to be short and the output is zero. Depending upon the output, it turns the pump ON/OFF.

\subsection{Ultrasonic Sensor}

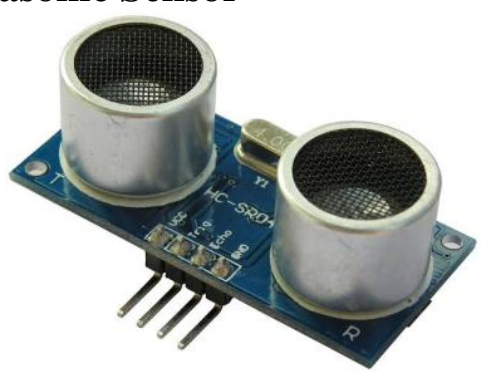

Fig 6: Ultrasonic Sensor

Ultrasonic module provides $2 \mathrm{~cm}-400 \mathrm{~cm}$ non-contact measurement; this ranging can reach upto $3 \mathrm{~mm}$. It has ultrasonic transmitter, receiver and feedback circuit. An electrical pulse of high voltage is applied to the ultrasonic transducer it generates vibration across selected spectrum of frequencies and produces a burst of sound waves. Whenever an obstacle comes in front to the ultrasonic sensor the sound waves reflect back and generates an electrical pulse. The time taken between sending sound waves and receiving echo is calculated.

The receiving echo is then picked up by the receiver and outputs a waveform with a time period proportional to the distance. The connected microcontroller accepts the signal and performs necessary processing.

\subsection{PIR Sensor}

PIR sensors allows to sense motion within the sensors range. It is small, low cost and power, easy to use. These sensors are commonly found in appliances and gadgets used in homes or businesses.

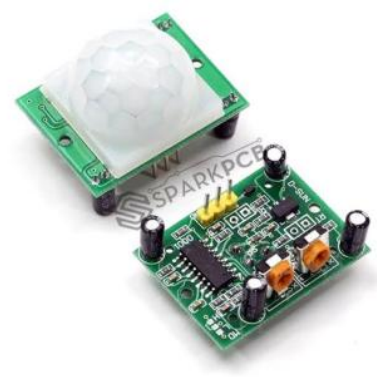

Fig 7: PIR Sensor

PIR sensor detects somebody's being traveling within $10 \mathrm{~m}$ from the sensor range. It is a median value because the actual detection range is between $5 \mathrm{~m}$ and $12 \mathrm{~m}$ and the power is typically up to $5 \mathrm{~V}$.

\subsection{Flame Sensor}

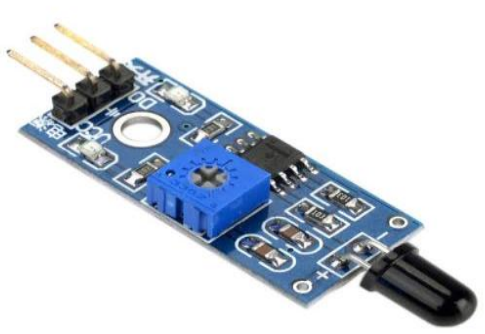

\section{Fig 8: Flame Sensor}

A Flame sensor is one kind of detector for detecting and responding to the occurrence of a fire or flame. The response of this sensor is faster as well as more accurate compare with a heat/smoke detector because of its mechanism while detecting the flame. This sensor detects flame otherwise wavelength within the range of $760 \mathrm{~nm}-1100 \mathrm{~nm}$ from the light source.

\subsection{Rain Sensor}

A Rain sensor is a kind of switching device which is used to detect the rainfall. It is used as a switch when raindrop falls through the raining board and also for measuring rainfall intensity. The module features, a rain board and the control 
board that is separate for more convenience, power indicator LED and an adjustable sensitivity though a potentiometer.

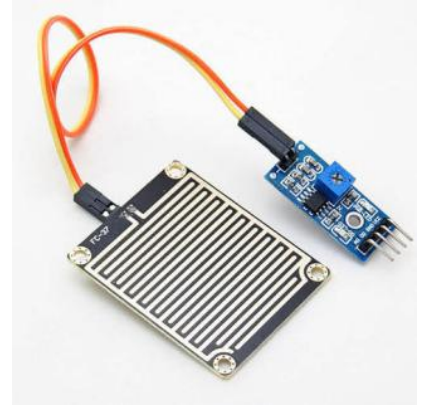

Fig 9: Rain Sensor

\subsection{Relay}

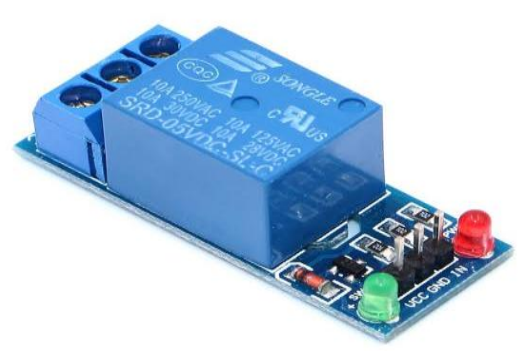

Fig 10: Relay

A Relay may be an electrically operated switch. Many relays use an electromagnet to mechanically operate a switch. Relays are used where it's necessary to manage a circuit by a separate low -power signal. For the aim of controlling the relay is employed here.

\section{Interfacing with Motor}

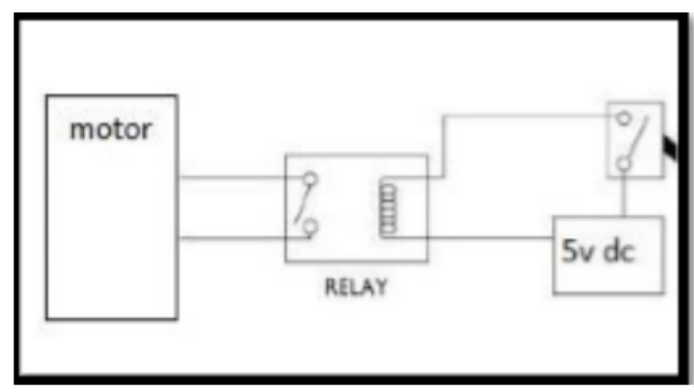

Fig 11: Relay with Motor

Relay is interfaced with motor shown in Fig. 10 to pump the water to the field. It will artificially supply water to the field whenever water is needed and electronically controlled by interfacing it to a raspberry $\mathrm{Pi}$. It can be triggered ON/OFF by sending signals as required. The process of artificially supplying water is known as pumping. There are many varieties of water pumps used. This work employs the use of a submersible water pump which is connected to power supply through relay.

\subsection{Python IDLE}

Integrated Development and Learning Environment (IDLE) is an Integrated Development Environment (IDE) for Python.
IDLE is used to execute a single statement just like Python Shell and also to create, modify and execute Python scripts. IDLE provides a fully-featured text editor to create Python scripts that includes features like syntax highlighting, auto completion and smart indent. It also has a debugger with stepping and breakpoints features.

\subsection{Thing Speak}

Thing Speak is IoT Cloud platform where it will send sensor data to the cloud. This can analyze and visualize data with MATLAB or other software, making own applications. This includes an internet Service (REST API) that permits to collect and store sensor data within the cloud and develop Internet of Things applications.

\section{EXPERIMENTAL RESULTS}

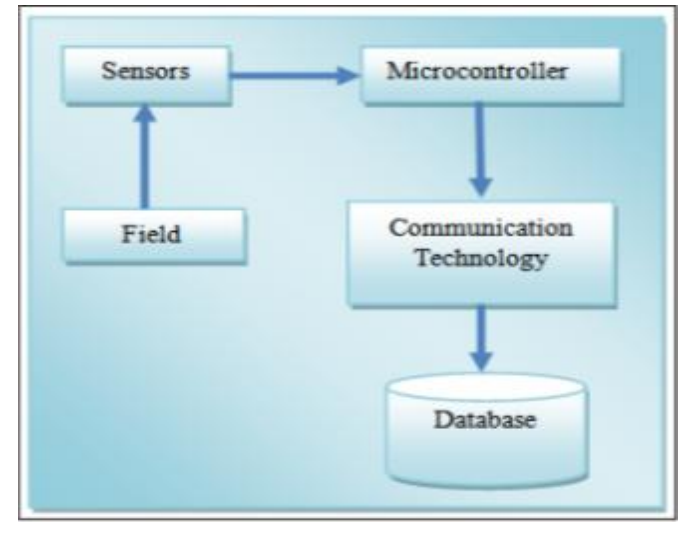

Fig 12: Block diagram of working representation

The system could be a combination of hardware and software. The sensors are connected with the Raspberry Pi board and it provides input to the controller. Figure 12 shows the working representation. The $\$ 64000$ time sensed data are then stored at the cloud for further deciding. By storing the data, its ease for farmers to look at the knowledge from Thing speak web or application in their mobile.

This platform provides readings of every sensor used. It also advices the user to plant the crops based upon the temperature and climate as respect to the crop suggestions that are feed into the cloud platform. Whenever an animal enters into the farm area, the PIR and Ultrasonic sensor detects the presence of the animal and send the signal to the controller. It also generates a burst of sound waves within the kind of electric pulses to send the animal out of the farm. Fig. 13 and Fig.14 shows the Live data of Temperature and Humidity from IoT (Thingspeak). 


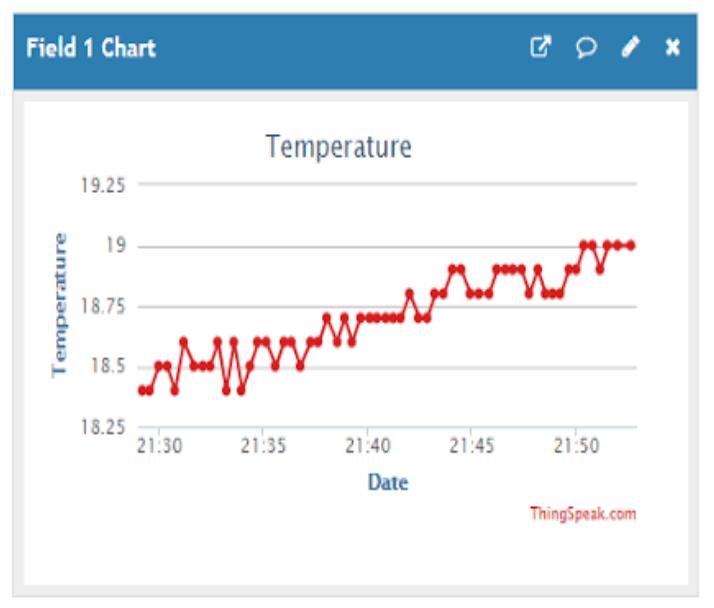

Fig 13: Live data of Temperature from Thing Speak

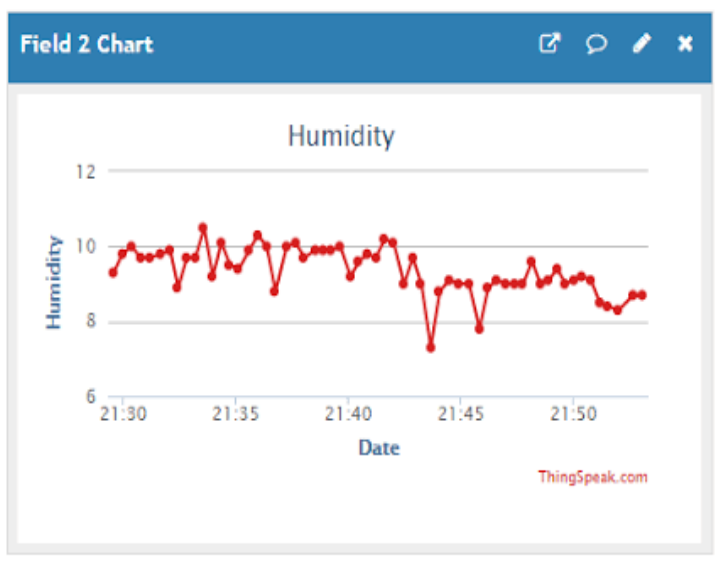

Fig 14: Live data of Humidity from Thing Speak

\section{CONCLUSION}

This work proposes an automated farming system to enhance the yield of crops with the help of smart IoT and cloud computing system. The sensed data will transmit through IoT and can be portrayed by the system to take corrective and preventive measures. This system is developed to provide optimal IoT architecture for agriculture in order to enhance the quality and quantity of products, save resources like water and electricity, economically efficient crop that cost less and make more profit to Indian farmers. In future, Effective farming can be done by collaborating machine learning techniques with web server to take intelligent decisions. Future work would be focused more on increasing sensors on this system to fetch more data especially with regard to Pest Control and by also integrating artificial intelligence to enhance this agriculture IoT technology to full-fledged automated system.

\section{REFERENCES}

[1] Asres Temam Abagissa, Ashutosh Behura, Santosh Kumar Pani, "IoT based Smart Agricultural Device Controlling System", 2nd International Conference on Inventive Communication and Computational Technologies (ICICCT), ISBN:978-1-5386-1974-2, 2018.

[2] Shweta B. Saraf, Dhanashri H.Gawali, "IoT Based Smart Irrigation Monitoring and Controlling System", 2nd IEEE International Conference on Recent Trends in Electronics Information \& Communication Technology (RTEICT), 978-1-5090-3704-9, 2017 IEEE.

[3] Abhishek Kumar, Magesh. S, "Automated Irrigation System Based on Soil Moisture Using Arduino", International Journal of Pure and Applied Mathematics Vol. 116, No.21, pp 319-323, 2017.

[4] Rahul Dagar, Subhranil Som, Sunil Kumar Khatri, "Smart Farming - IoT in Agriculture", International Conference on Inventive Research in Computing Applications (ICIRCA),978-1-5386-2456-2, 2018 IEEE.

[5] Prajna. P, Soujanya B.S, Divya, "IoT- based Wild Animal Intrusion Detection System", International Journal of Engineering Research \& Technology (IJERT), Vol.6, Issue 15, 2018.

[6] Mrs.R.Rajalakshmi, M.Atshaya Kiruthika, K.Muthumari, R.Muthu priya, "IoT Based Smart Farming Using Cloud Computing", International Journal Of Engineering Research and Technology (IJERT), Vol. 07, No. 01, ISSN: 2278-0181, 2019.

[7] Shruti Bansod, Rishita Jaiwal, Priyanka Sargam , Prajakta Survase, "Arduino Based Water Irrigation System", International Journal of Advance Research In Science and Engineering (IJARSE),Vol. 07, No. 03, ISSN: 2319-8354, April 2018.

[8] Vikhram.B, Revathi.B, Shanmuga Priya.R, Sowmiya.S, Pragadeeswaran, "Animal Detection System in Farm Areas", International Journal of Advance Research In Computer and Communication Engineering (IJARCCE), Vol.06, Issue 3, March 2017.

[9] Hemalatha, G. Deepika, D. Dhanalakshmi, K. Dharanipriya, M.Divya, "Internet of Things (IoT) based Smart Irrigation", International Journal of Advanced Research in Biology Engineering Science and Technology (IJARBEST), Vol.02, Issue 2, February 2016.

[10] Ashwini.C, Diparna Adhikary, Amisha Mishra, Shruti Duggal, "Automatic Irrigation System using Arduino", International Research Journal of Engineering and Technology (IRJET), Vol.05, Issue 10, October 2018.

[11] D.Mohanapriya, K.Keerthika, M.Anitha, L.Dharani, Sathyapriya, "Intelligence Iot Based Fishermen Border Inspection System (SSRG-IJECE)”, March 2019. 